\title{
Decreased sniffing behavior in rats following septal lesions
}

\author{
ERNEST D. KEMBLE and JENNIFER A. NAGEL \\ University of Minnesota, Morris, Minnesota 56267
}

\begin{abstract}
Sniffing behavior directed toward a localized source of conspecific urine was examined in rats with septal lesions. The lesions significantly reduced both the number and duration of sniffing bouts directed toward this source of stimulation. These results suggest that septal lesions alter behavioral responsiveness to olfactory stimuli.
\end{abstract}

Septal lesions alter reactivity to auditory, gustatory, visual, and thermal stimuli (e.g., Beatty \& Schwartzbaum, 1968: Brown \& Remley, 1971; Clody \& Carlton, 1969; Lints \& Harvey, 1969). Despite the fact that the septal area receives both direct and indirect olfactory connections (Powell, 1963; Powell, Cowan, \& Raisman, 1965), however, there has been little investigation of altered reactivity to olfactory stimuli following septal damage. This experiment was prompted by a series of observations of open field behavior among rats with septal lesions (Kemble \& Nagel, in press). These lesions seemed to increase the tendency of rats to stop during locomotor exploration and to sniff intensely at small floor areas which contained no obvious stimulus (e.g., feces, hair, urine) for this behavior. In view of the olfactory connections of the septal area and the enhanced reactivity to other forms of stimulation which follow its destruction, it seemed possible that increased floor sniffing resulted from enhanced reactivity to conspecific odor traces remaining after routine intersubject floor cleaning. If this analysis is correct, it might also be expected that septal lesions would alter reactivity to a highly localized source of conspecific odor. This experiment explores this possibility.

\section{METHOD}

\section{Subjects}

The subjects were 21 male albino rats (Holtzman Company) weighing 320-370 g. Thirteen subjects had previously served in two brief $(5 \mathrm{~min})$ tests of rearing behavior in an open field. Eight (normal control) rats were experimentally naive.

\section{Surgery and Histology \\ Septal lesions were produced in six rats by passing $2.0-\mathrm{mA}$ anodal $\mathrm{dc}$ for $20 \mathrm{sec}$ through the uninsulated tip of a stainless steel pin. Two rats received control operations while five rats received scalp incisions only. Eight (normal control) rats received no surgical treatment. At the conclusion of testing, 24 micron coronal sections were prepared through all lesions and stained with cresyl violet for histological examination. All lesions included bilateral damage to the precommissural portions of the medial and lateral septal nuclei. There was no discernible relationship between lesion size and/or placement and}

The authors would like to thank Gloria Rixen who aided in data collection. performance in thị experiment. Reconstructions of representative lesions are available in another publicaton (Kemble \& Nagel, in press).

\section{Apparatus}

Testing was conducted in a $28.6 \times 33 \times 34.3 \mathrm{~cm}$ compartment with a floor and three walls of $1.3-\mathrm{cm}$ plywood painted with clear varnish. One wall and the ceiling was of clear Plexiglas. A small $(.9-\mathrm{cm}$ diam) hole was placed $3.2 \mathrm{~cm}$ above the floor and $4.5 \mathrm{~cm}$ from an end wall. Into this hole was inserted the $(.9-\mathrm{cm}$ o.d.) $2.5-\mathrm{cm}$-long neck of a funnel $(10.2 \mathrm{~cm}$ diam at mouth) until flush with the inner wall of the compartment. Extraneous noise was masked by $90 \mathrm{~dB}$ white noise, and illumination was provided by a $40-\mathrm{W}$ bulb placed $20.3 \mathrm{~cm}$ above the apparatus.

\section{Procedure}

The odorous substance used in this experiment was the urine of a male albino rat (not a subject in this experiment) which was collected for $24 \mathrm{~h}$ prior to the experiment. Immediately before each rat was tested, the floor and walls of the apparatus were cleaned with a damp sponge, a clean cotton swab was saturated with urine, and the inner $5.0 \mathrm{~cm}$ of the funnel and approximately $1.3 \mathrm{~cm}$ of the neck was dampened with urine and inserted in the apparatus. The rat was placed in the compartment for $10 \mathrm{~min}$, and the number of times the rat touched or inserted its snout into the funnel neck was recorded with a (Aristo) hand counter. The duration of each sniffing bout was recorded by stopwatch. Normal rats $(N=8)$ were tested in this apparatus for $10 \mathrm{~min}$ with no odorous material in the funnel. These animals made $0-8$ contacts with the nonodorized funnel $(\overline{\mathrm{X}}=3.6)$ with an average duration of $1.2 \mathrm{sec}$ per contact (range, $.5-7.7 \mathrm{sec}$ ).

\section{RESULTS AND DISCUSSION}

Subjects with septal lesions engaged in significantly fewer sniffing bouts $(\overline{\mathrm{X}}=2.7)$ than operated control $(\overline{\mathrm{X}}$ $=8.4)$ animals, Mann-Whitney $[\mathrm{U}(6,7)=3, \mathrm{p}<.02]$. Moreover, the average duration of each sniffing bout was significantly shorter among rats with septal lesions $(\overline{\mathrm{X}}=$ $1.3 \mathrm{sec})$ than operated control $(\overline{\mathrm{X}}=2.8 \mathrm{sec})$ rats, Mann-Whitney $[\mathrm{U}(6,7)=4, \mathrm{p}<.02]$. The sniffing bouts of the operated control rats were more frequent, Mann-Whitney $[\mathrm{U}(7,8)=9, \mathrm{p}<.03]$, and of longer average duration, Mann-Whitney $[\mathrm{U}(7,8)=9, \mathrm{p}<.03]$, than those of the eight normal control rats tested without urine odors in the funnel. Thus, male urine was effective in increasing sniffing bouts among normal rats. Since rats with septal lesions were not tested under 
no-odor conditions, it is conceivable that reduced funnel sniffing among the brain-damaged rats reflected reduced exploratory behavior. The failure of very similar lesions -to alter open field activity during a 10-min test (Kemble $\&$ Nagel, in press) seems to argue against this possibility, however. Also, the low levels of funnel sniffing among normal rats under no-odor conditions (three rats failed to sniff the funnel during the test) make it unlikely that a lesion effect would emerge under nonodor conditions.

These results suggest that septal lesions decrease, rather than increase, sniffing behavior directed toward conspecific olfactory stimuli. This finding may be interpreted as reflecting increased reactivity to some (presumably aversive) components of the conspecific odors used in this experiment. If so, it is difficult to understand why normal rats increased sniffing behavior toward the funnel when conspecific urine was present. Alternatively, it may be that septal lesions decrease reactivity to some odors or show intensity specific effects. Since completion of this experiment, however, Carlson and Vallante (1974) have reported increased reactivity to olfactory discriminative stimuli among mice with septal lesions. Thus, lesion-induced enhancement in reactivity to odors does occur under some test conditions. Since the present experiment differed in important ways (including use of different odors) from those of Carlson and Vallante (1974), it is difficult to compare the results of the two experiments. It is quite possible, for example, that increased reactivity would be observed in the present test if other odors, or different concentrations of conspecific odors, were used. Taken together, the present results and those of Carlson and Vallante (1974) do indicate that septal lesions alter behavioral responsiveness to odors. Further investigation of this phenomenon is clearly needed.

\section{REFERENCES}

Beatty, W. W., \& Schwartzbaum, J. S. Consummatory behavior for sucrose following septal lesions in the rat. Journal of Comparative and Physiological Psychology, 1968, 65, 93-102.

Brown, G. E., \& Remley, N. R. The effects of septal and olfactory bulb lesions on stimulus reactivity. Physiology and Behavior, 1971, 6, 497-501.

Carlson, N. R., \& Vallante, M. A. Enhanced cue function of olfactory stimulation in mice with septal lesions. Journal of Comparative and Physiological Psychology, 1974, 87, 237-248.

Clody, D. E., \& Carlton, P. L. Behavioral effects of lesions of the medial septum of rats. Journal of Comparative and Physiological Psy chology, 1969, 67, 344-351.

Kemble, E. D., \& Nagel, J. A. Persistent depression of rearing behavior in rats following extensive septal lesions. Journal of Comparative and Physiological Psychology, in press.

Lints, C. E., \& Harvey, J. A. Altered sensitivity to footshock and decreased brain content of serotonin following brain lesions in the rat. Journal of Comparative and Physiological Psychology, 1969, 67, 23-32.

Powell, E. W. Septal efferents revealed by axonal degeneration in the rat. Experimental Neurology, 1963, 8, 406-422.

Powell, T. P. S., Cowan, W. M., \& Raisman, G. The central olfactory connexions. Journal of Anatomy, 1965, 99, 791-813.

(Received for publication January $1,1975$. ) 